Article

\title{
Evaluation of Psychotropic Drug Use in Adolescents Accessing a General Emergency Medical Department for Mental Disorders
}

\author{
Martina Buttera ${ }^{1}$, Antonio Clavenna ${ }^{1} \oplus$, Lucia Tansini ${ }^{2}$, Erica Maselli ${ }^{2}$, Alessandro Albizzati ${ }^{2}$, \\ Maria Paola Canevini ${ }^{2,3}$ and Maurizio Bonati ${ }^{1, * \mathbb{D}}$ \\ 1 Laboratory for Mother and Child Health, Department of Public Health, Istituto di Ricerche Farmacologiche \\ Mario Negri IRCCS, 20156 Milan, Italy; martina.buttera@studenti.unimi.it (M.B.); \\ antonio.clavenna@marionegri.it (A.C.) \\ 2 Child Neuropsychiatric Unit—San Paolo Hospital, 20142 Milan, Italy; luciatansini@gmail.com (L.T.); \\ erica.maselli@gmail.com (E.M.); alessandro.albizzati@ao-sanpaolo.it (A.A.); \\ maria.canevini@ao-sanpaolo.it (M.P.C.) \\ 3 Department of Health Sciences, Università degli Studi di Milano, 20122 Milan, Italy \\ * Correspondence: maurizio.bonati@marionegri.it
}

Received: 28 September 2020; Accepted: 18 November 2020; Published: 24 November 2020

\begin{abstract}
Background: Given the paucity of data concerning the care of adolescents attending an emergency department (ED) for mental disorders, we performed an observational study with the aim to describe psychotropic drug use in an Italian ED. Methods: A retrospective chart review of adolescents (13-17 years) visited in the ED of the San Paolo University Hospital in Milan for mental disorders between January and June 2018 was conducted. Information concerning age, gender, type of disorder, psychotropic drug use in the ED and outcome of the visit were analyzed, using an anonymous patient code. Results: A total of 1298 adolescents, 13-17 years old, were visited in the ED, $56(4 \%)$ of whom had a diagnosis of mental disorder (34 females and 22 males). The most common disorder was anxiety (21 patients), followed by predominant psychomotor disorder (13 patients). In all, 30 adolescents received a psychotropic drug. Benzodiazepines were the most commonly used drugs ( $73 \%$ of the subjects), and delorazepam was administered/prescribed to 17 adolescents, despite the fact that evidence on its safety, efficacy, and its off-label use in the pediatric population is lacking. Conclusions: One out of two adolescents attending the ED for an acute episode of mental disorder received a psychotropic drug prescription, mainly in an off-label manner. More evidence is needed to guide the pharmacological management of acute episodes of mental disorders.
\end{abstract}

Keywords: adolescent; emergency department; drug prescription; mental disorders; off-label prescription; psychotropic drug

\section{Introduction}

Psychiatric disorders, neurological pathologies, and substance abuse actually represent $13 \%$ of the global burden of disease in the world's population [1]. Mental health, however, is largely ignored worldwide, especially when it concerns services and resources for children and adolescents. Nowadays, neuropsychiatric disorders involve $13.4 \%$ of children and adolescents, $25 \%$ of whom present serious symptoms with different disorders, such as language disorder, attention deficit hyperactivity disorder (ADHD), autism, depression, and intellectual disability [2].

The emergency department (ED) has become an important gateway for access to mental health services for children and youth due to limited access and long waiting times for specialized assessment and services [3,4]. Both international and Italian studies show that ED visits for mental health disorders 
account for $1 \%$ to $5 \%$ of pediatric emergency visits [5-9]. Moreover, from $70 \%$ to $84 \%$ of individuals presenting to pediatric emergency mental health services are adolescents, and mostly females [7,10-12]. Studies focusing on adolescents accessing the ED for psychiatric disorders reported mood disorders $(9-63 \%)$, agitation $(21-33 \%)$, and anxiety $(5-21 \%)$ as the most common diagnosis at discharge [10-12].

The pattern of psychotropic drug prescription in outpatient children and adolescents is largely described [13], but little is known concerning therapies administered or prescribed in the ED setting $[14,15]$. This finding does not reflect the increased use of emergency care services for acute episodes of mental disorders, in particular for anxiety and depressive symptoms [11,12], while the ED physicians may be required to establish the first therapeutic interventions. It is, therefore, important to monitor the profile of psychotropic drugs used in the emergency departments.

In Italy, anyone needing emergency care can refer to an ED on any day or night of the week. Access is always free of charge for children younger than 14, while older children and adults pay a fee for non-urgent visits. Triage codes are assigned by triage nurses and consist of four categories, based on nation-wide criteria: Red (non-deferrable emergency, life-threatening condition), yellow (urgent, but not immediate life-threatening condition), green (low urgency and priority, deferrable care), and white code (non-urgent) [16].

For children and adolescents, mental health care is provided by child and adolescent neuropsychiatry services (CANPS) that are part of the local health unit (LHU). CANPS are multi-professional, comprehensive community services providing diagnosis, treatment, and rehabilitation. They are separate from adult mental health services and work mainly on an outpatient basis, in close connection with educational and social services.

The present study aims to analyze the characteristics of ED accesses for psychiatric reasons, and to evaluate the pattern and appropriateness of psychotropic drugs prescribed to adolescents with acute mental disorders accessing the ED of a polyclinic hospital.

\section{Materials and Methods}

\section{Data Source and Analyses}

The San Paolo Hospital is both a public polyclinic facility of the National Health Service and a university campus located in Milan, Italy. The hospital at the time of the study did not have a child psychiatric ward.

Clinical health records of adolescents (13-17 years old) with psychiatric disorders who accessed the ED for psychiatric reasons from 1 January and 30 June 2018 were analyzed to carry out the present analytical observational study.

An anonymous alphanumeric code for patient identification was associated with each access that required a visit by a child psychiatrist (present in the ED from 8 am to 4:30 pm from Monday to Friday) or a psychiatrist (present in the ED $24 \mathrm{~h}$ /day). Patients visited by a child psychiatrist for neurological reasons were not considered in the study, nor were adolescents with traumatic injuries.

No ethics committee approval is required in Italy for epidemiological studies using healthcare administrative databases for research purposes and with individuals identified by an anonymous patient code.

Besides patients' sociodemographic information (age, gender, and place of birth) for each psychiatric access, the date and time of entry and discharge, arrival with ambulance, and triage code assigned were extracted. Subjects who had not attended the ED before, had never had contact with psychiatric services, had never assumed psychotropic drugs, and were not in therapy at the time of access to the ED were considered naïve patients.

The principal psychiatric reason for referral, the main psychiatric discharge diagnosis (code ICD-9), the presence of any psychiatric comorbidities, and the administration/prescription of psychotropic drugs were also evaluated. Diagnoses were classified on the basis of ICD-9 codes as: "anxiety disorders" (ICD-9 codes 293.84, 300.01, 309.24, 300.11), "predominant psychomotor 
disturbance" (308.2), "mood disorders" (296.90, 311.00, 309.28), "borderline personality disorders" $\left(301^{*}\right)$, "psychosis" (298.00 and 298.10), and "others" (psychiatric disorders not comprised in the previous groups).

Psychotropic drugs were defined according to the World Health Organization categories and comprised the following subgroups of the Anatomic Therapeutic Chemical (ATC) classification system: Antipsychotics (N05A), benzodiazepine derivatives (N05BA), antidepressants (N06A), centrally acting sympathomimetics (ADHD medications, N06BA), and anticonvulsants (N03). The prevalence of psychotropic drug use, estimated as the proportion of adolescents with a drug administration and/or prescription on the total number of adolescents attending the ED for mental disorders, was the main outcome measure.

For the comparison of proportions and categorical variables, the chi-square test was used. In particular, a comparison of the prevalence of psychotropic drug use was performed for the following variables: Gender, age, group of disorders (anxiety, predominant psychomotor disturbance, other disorders), physician specialty (child psychiatrist versus psychiatrist), urgency of the visit, and naïve versus non-naïve patients. The comparison by gender and age was performed using a Mantel-Haenszel chi-square test. A $p$-value $<0.05$ was considered statistically significant.

\section{Results}

Between 1 January 2018 and 30 June 2018, 1298 patients, 13-17 years old (male/female ratio 1.07), whose median age was 15 years and 168 of whom were foreigners (13\%), attended the ED. A total of 56 adolescents $(4 \%)$ were visited for psychiatric reasons (Table 1), and among these, the median age was 16 years, the male/female ratio was 0.65 , and the proportion of foreigners was $21 \%$. A slight difference in the rate of ED access by gender was observed: The proportion of adolescents referring to the ED for mental health disorders was slightly higher in females (34 out of a total of $626,5 \%$ ) than in males ( 22 out of $672,3 \%$ ). Moreover, the percentage of children not born in Italy was higher if compared to the group attending for non-psychiatric reasons.

Half of the psychiatric patients (51\%) arrived at the ED by ambulance, and 20 patients $(36 \%)$ received a yellow or red triage code. Anxiety disorders were diagnosed in $37.5 \%$ of patients, followed by predominant psychomotor disorders (23.2\%), and mood disorders (10.7\%) (Table 1). In all, five adolescents with personality or mood disorders were visited in the ED for self-harm, in two cases associated with suicidal ideation.

A total of 26 adolescents (46.4\%) had one or more psychiatric comorbidities, in particular bipolar disorder.

In all, 30 patients (54\%) received at least one psychotropic drug in the ED (administered or prescribed), with a higher prevalence among adolescents with anxiety disorders $(71 \%)$, and predominant psychomotor disorders $(62 \%)\left(x^{2}=7.2, p\right.$-value $\left.=0.027\right)$. Overall, in 16 patients drugs were administered in the ED, while in 19 patients drugs were prescribed at discharge, with five patients having both administered and prescribed drugs. There was no difference by age in the prevalence of drug use, while boys received drugs more frequently than girls: $72 \%$ versus $41 \%$, respectively $\left(\mathrm{x}^{2} \mathrm{M}-\mathrm{H}=4.619\right.$; $p$-value $=0.04$ ). In particular, the prevalence of pharmacological intervention was about two-fold higher in males $\geq 16$ years old ( $p$-value $=0.004$ ), while in subjects less than 16 years old, no gender difference was observed.

No statistically significant differences were observed in the prevalence of drug prescription in urgent versus non urgent visits $\left(x^{2}=0.02 ; p=0.90\right)$, nor in adolescents born in Italy versus those not born in Italy $\left(x^{2}=0.14 ; p=0.71\right)$.

A total of 13 active psychotropic substances (seven benzodiazepines, five antipsychotics, and valproic acid) were prescribed or administered in the ED (Table 2). Benzodiazepines were the most used drugs ( $73 \%$ of the treated patients), followed by antipsychotics, with delorazepam being used in $17 / 30$ patients $(57 \%)$. 
Six patients received a polytherapy prescription, and, in one case, two different psychotropic drugs (olanzapine and risperidone) were administered in the ED.

In all, 32 patients ( $57 \%$ ) were visited by child psychiatrists, 23 by psychiatrists, and for one patient, this information was not available. A greater prevalence of drug use was observed among adolescents visited by child psychiatrists, compared to those visited by psychiatrists (65\% versus $39 \%$, respectively; $x^{2}=2.8 ; p=0.09$ ). Even when stratified by disorder, the percentage of patients treated with drugs was higher among adolescents visited by child psychiatrists. Delorazepam was the most prescribed drug by both child psychiatrists and psychiatrists, while alprazolam and bromazepam were prescribed only by child psychiatrists, and diazepam, midazolam, quetiapine, and promazine by psychiatrists (Table 2).

In all, 10 patients $(18 \%)$ were hospitalized after the ED visit (Table 1$)$.

A total of 17 patients (14 girls and 3 boys) were naïve: 15 had anxiety disorders, one boy had a borderline personality disorder, and one girl had psychomotor agitation. Three adolescents were hospitalized after the visit, 11 were discharged with outpatient indications, and three were discharged. Nine subjects received a drug therapy: Seven girls and two boys. There were no statistically significant differences in the prevalence of drug use in naïve versus non-naïve adolescents $\left(x^{2}=0.05 ; p=0.82\right)$.

Delorazepam was administered and/or prescribed to eight out of nine adolescents. Diazepam $(n=1)$, lorazepam $(n=1)$, and flurazepam $(n=1)$ were also used.

Table 1. Characteristics of adolescents visited for psychiatric reasons and of those receiving a psychotropic drug.

\begin{tabular}{|c|c|c|c|}
\hline \multirow{2}{*}{ Variable } & & Mental Disorders & Psychotropic Drug \\
\hline & & $(n=56)$ & $(n=30)$ \\
\hline \multirow{2}{*}{ Gender } & Male & 22 & 16 \\
\hline & Female & 34 & 14 \\
\hline \multirow{2}{*}{ Age (years) } & $13-15$ & 24 & 11 \\
\hline & $16-17$ & 32 & 19 \\
\hline \multirow{2}{*}{ Born in Italy } & Yes & 44 & 21 \\
\hline & No & 12 & 7 \\
\hline \multirow{2}{*}{ Out-of-hours } & Yes & 18 & 8 \\
\hline & No & 38 & 22 \\
\hline \multirow{2}{*}{ Urgent visit } & Yes & 20 & 11 \\
\hline & No & 36 & 19 \\
\hline \multirow{2}{*}{ Physician } & Child psychiatrist & 32 & 21 \\
\hline & Psychiatrist & 23 & 9 \\
\hline Naive & Yes & 17 & 9 \\
\hline \multirow{6}{*}{ Diagnosis } & Anxiety disorders & 21 & 15 \\
\hline & Predominant psychomotor disturbance & 13 & 8 \\
\hline & Mood disorders & 6 & 3 \\
\hline & Borderline personality disorder & 5 & 3 \\
\hline & Psychosis & 5 & 1 \\
\hline & Others & 6 & 0 \\
\hline \multirow{4}{*}{ Outcome } & Discharged with outpatient indications & 30 & 17 \\
\hline & Hospitalization & 10 & 3 \\
\hline & Discharged to home & 10 & 7 \\
\hline & Discharged to the child-care home & 5 & 3 \\
\hline
\end{tabular}


Table 2. Psychotropic drugs administered and/or prescribed to adolescents attending the San Paolo Hospital ED for mental disorders.

\begin{tabular}{ccccc}
\hline Active Substance & $\boldsymbol{n}$. Child-Psychiatrists & Psychiatrists & Disorder \\
\hline Delorazepam & 17 & 12 & 5 & $\begin{array}{c}\text { Anxiety disorders: } 9 \\
\text { Psychomotor disturbance: } 6 \\
\text { Personality disorder: } 1 \\
\text { Psychosis: } 1\end{array}$ \\
\hline Alprazolam & 4 & 4 & - & $\begin{array}{c}\text { Anxiety disorders: } 3 \\
\text { Personality disorder: } 1\end{array}$ \\
\hline Olanzapine & 4 & 2 & 2 & $\begin{array}{c}\text { Anxiety disorders: } 1 \\
\text { Mood disorder: } 1\end{array}$ \\
\hline Lorazepam & 3 & 2 & 1 & $\begin{array}{c}\text { Psychosis: } 1 \\
\text { Psychomotor disturbance: } 1\end{array}$ \\
\hline Aripiprazole & 2 & 1 & 1 & $\begin{array}{c}\text { Anxiety disorders: } 1 \\
\text { Mood disorder: } 1\end{array}$ \\
\hline Flurazepam & 2 & 1 & 1 & $\begin{array}{c}\text { Anxiety disorders: } 1 \\
\text { Mood disorder: } 1\end{array}$ \\
\hline Risperidone & 2 & 1 & 1 & Psychomotor disturbance: 2 \\
\hline Bromazepam & 1 & 1 & - & Anxiety disorders: 1 \\
\hline Diazepam & 1 & - & 1 & Anxiety disorders: 1 \\
\hline Midazolam & 1 & - & - & Anxiety disorders: 1 \\
\hline Promazine & 1 & 1 & 1 & Personality disorder: 1 \\
\hline Quetiapine & 1 & - & Psychomotoror disturbance: 1 \\
\hline
\end{tabular}

\section{Discussion}

To the best of our knowledge, this is the first study to evaluate the management of acute psychiatric symptoms in adolescents in an Italian ED.

Overall, four out of 100 accesses to the ED by adolescents occurred for psychiatric reasons, a figure consistent with the rate of 1-5\% paediatric ED accesses observed in previous international studies [5-9].

Adolescents referring to the ED for mental disorders were mostly females, as also found in other studies [10,12]. Moreover, there was a slightly higher prevalence of patients not born in Italy when compared to adolescents referring to the ED for non-psychiatric reasons. Female gender and place of birth can, therefore, be considered as potential determinants of ED use for mental disorders in adolescents.

As expected, we observed both a five-fold higher percentage of patients with urgent (yellow/red) triage code than the one usually observed in the pediatric population referring to the ED for non-psychiatric reasons (36\% versus $6 \%$ ) and a greater hospital admission rate [16].

Anxiety disorders and predominant psychomotor disorders were the most frequent diagnoses. The prevalence of diagnosis of psychomotor disorders in the sample (23\%) is consistent with findings of other studies regarding adolescents $(21-33 \%)$, while a greater proportion of anxiety disorders (36\% versus $5-21 \%$ ) was found [10-12].

In our sample, more than half of the patients received psychotropic drugs in the ED, data consistent with the proportion reported in the United States [14].

A total of 13 psychotropic drugs were used in the ED. In particular, there was a large use of benzodiazepines, while antipsychotics were less frequently administered or prescribed and antidepressants were never used. 
Male gender, diagnosis, and care provider emerged in our study as determinants that are potentially associated with a greater likelihood of receiving a drug. Two-thirds of patients with anxiety disorders or predominant psychomotor disorders received a psychotropic medication, while those with other disorders were less frequently treated. Adolescents visited by a child psychiatrist received a drug more frequently than those visited by a psychiatrist, a fact that could be associated with a different attitude in drug use between the two specialists.

Regardless of the diagnosis, delorazepam was the most used drug. This medication is not registered for paediatric use (unlicensed), and its large use is debatable if considering the availability of other benzodiazepines that are registered for the pediatric age, such as lorazepam (licensed for children $\geq 12$ years old). It is very odd that seven different benzodiazepines were used, considering the small number of adolescents receiving a psychotropic drug and that only one ED was monitored. This may reflect different preferences in drug choice by each physician.

Anxiolytics and antidepressants are the drug therapies that have been evaluated in clinical trials for the management of anxiety disorders in the pediatric population. With the exception of lorazepam, at least in Italy, benzodiazepines are unlicensed for pediatric use and evidence of their safety and efficacy in the pediatric age is scant. Only two randomized controlled trials (RCTs) have evaluated the efficacy of benzodiazepines in the pediatric population with anxiety disorders, showing no differences between clonazepam or alprazolam versus placebo $[17,18]$.

Antidepressant drugs are considered an effective therapy for pediatric anxiety disorders, but this drug class was not prescribed in our study [19-21]. This could be due to the fact that the pharmacological treatment was aimed at acute symptom management, while consideration of long-term therapy may be left to the hospital or territorial CANPS.

According to the available data, effective and safe management of agitation includes both non-pharmacological and pharmacological strategies [15,22-24].

There are no RCTs evaluating the pharmacological management of this condition in the pediatric population in the ED. In a Cochrane review, limited evidence of the efficacy of risperidone was found [25], while NICE guidelines suggest that this drug may be considered for the short-term treatment of aggressive behavior in the pediatric population with conduct disorders [26].

Nevertheless, the use of benzodiazepines (lorazepam) or antipsychotics (haloperidol, olanzapine, risperidone, and ziprasidone) for the rapid tranquilization of children and adolescents with agitation is widely recommended [15,22-24].

Despite the lack of evidence of efficacy, delorazepam was identified as the first-choice pharmacological treatment for agitation in children and adolescents in a local protocol set up by a group of psychiatrists and child-psychiatrists in the Lombardy Region, and this may explain its frequent use [27].

Our study has some limitations that should be considered: it was performed in a single hospital ED and a small number of adolescents were monitored during the observation period. A multicentre study involving multiple EDs and with a larger sample is needed to confirm our results. An additional limitation concerns the computerized ED files. These files collected very little clinical data and it is not possible to evaluate the occurrence and severity of symptoms in detail.

Few studies have evaluated the care of adolescents with acute episodes of mental disorders in emergency departments. Despite the small sample size, in our opinion, this study represents a pilot experience that could be replicated in other settings with the aim to monitor the prescription of psychotropic drugs in daily practice, identify the areas where more data on the effectiveness of treatments are needed (e.g., predominant psychomotor disorders), and develop therapeutic protocols and guidelines at local, national, and international levels. In particular, the finding that several different drugs were used, drugs for which, in many cases, no clinical trials involving the pediatric population were carried out, underlines the need for therapeutic approaches based on the available evidence.

One-half of mental disorders begin before adult age, and many disorders can represent a life-long source of dysfunction. An ecological framework for improving child and adolescent health is important 
for the present and future mental health of all [28]. New models of intervention delivery are needed, expanding mental health services so that they are able to respond effectively to the mental health needs [29,30] while also reducing and managing ED accesses.

\section{Conclusions}

Overall, $4 \%$ of adolescents, mostly females 16-17 years old, attending an ED had mental disorders. Almost half of the patients received drug treatment, and, in many cases, it was off-label and with scant evidence of efficacy. Anxiety, treated with benzodiazepines, was the most frequent disorder in adolescents attending an ED for mental disorders, suggesting that many accesses may be avoided through an improvement of the role and organization of primary care physicians and child psychiatry outpatient services. Systematic monitoring of the management of acute mental health disorders in adolescents in the emergency care setting is needed in order to identify the area of inappropriateness and unmet needs. This monitoring should include a follow-up of the clinical pathways and the outcomes of the patients visited in the ED. Finally, in our opinion, the existing protocols should be reviewed and updated, taking into account the available evidence, even if it is limited.

Author Contributions: Conceptualization, A.C., M.P.C. and M.B. (Maurizio Bonati); formal analysis: M.B. (Martina Buttera). and A.C.; data curation, M.B. (Martina Buttera), E.M., L.T.; writing-original draft preparation, M.B. (Martina Buttera) and A.C.; writing-review \& editing, E.M., L.T., A.A., M.P.C, M.B. (Maurizio Bonati); supervision A.A., M.P.C., M.B. (Maurizio Bonati). All authors have read and agreed to the published version of the manuscript.

Funding: This research received no external funding.

Conflicts of Interest: The authors declare no conflict of interest.

\section{References}

1. Vigo, D.; Thornicroft, G.; Atun, R. Estimating the true global burden of mental illness. Lancet Psychiatry 2016, 3, 171-178. [CrossRef]

2. Polanczyk, G.V.; Salum, G.A.; Sugaya, S.S.; Caye, A.; Rohde, L.A. Annual Research Review: A meta-analysis of the worldwide prevalence of mental disorders in children and adolescents. J. Child Psychol. Psychiatry 2015, 56, 345-365. [CrossRef] [PubMed]

3. Edelsohn, G.A.; Braitman, L.E.; Rabinovich, H.; Sheves, P.; Melendez, A. Predictors of Urgency in a Pediatric Psychiatric Emergency Service. J. Am. Acad. Child Adolesc. Psychiatry 2003, 42, 1197-1202. [CrossRef] [PubMed]

4. Chun, T.H.; Katz, E.R.; Duffy, S.J. Pediatric mental health emergencies and special health care needs. Pediatr. Clin. N. Am. 2013, 60, 1185-1201. [CrossRef]

5. Newton, A.S.; Ali, S.; Johnson, D.W.; Haines, C.; Rosychuk, R.J.; Keaschuk, R.A.; Jacobs, P.; Klassen, T.P. A 4-year review of pediatric mental health emergencies in Alberta. CJEM 2009, 11, 447-454. [CrossRef]

6. Mapelli, E.; Black, T.; Doan, Q. Trends in Pediatric Emergency Department Utilization for Mental Health-Related Visits. J. Pediatr. 2015, 167, 905-910. [CrossRef]

7. Holder, S.M.; Peterson, E.; Ochonma, C.; Rogers, K. Mental Health Visits: Examining Socio-demographic and Diagnosis Trends in the Emergency Department by the Pediatric Population. Child Psychiatry Hum. Dev. 2017, 48, 993-1000. [CrossRef]

8. Cozzi, G.; Minute, M.; Ventura, G.; Barbi, E. Mental Health Problems in Children and Adolescents in the Emergency Department. Pediatr. Emerg. Care 2017, 33, e8. [CrossRef]

9. Hiscock, H.; Neely, R.J.; Lei, S.; Freed, G. Paediatric mental and physical health presentations to emergency departments, Victoria, 2008-15. Med. J. Aust. 2018, 208, 343-348. [CrossRef]

10. Cuypers, P.J.; Danckaerts, M.; Sabbe, M.; Demeyttenaere, K.; Bruffaerts, R. The paediatric psychiatric emergency population in a university teaching hospital in Belgium (2003-2008). Eur. J. Emerg. Med. 2014, 21, 384-386. [CrossRef]

11. Kalb, L.G.; Stapp, E.K.; Ballard, E.D.; Holingue, C.; Keefer, A.; Riley, A. Trends in Psychiatric Emergency Department Visits Among Youth and Young Adults in US. Pediatrics 2019, 143, e20182192. [CrossRef] [PubMed] 
12. Benarous, X.; Milhiet, V.; Oppetit, A.; Viaux, S.; El Kamel, N.M.; Guinchat, V.; Guilé, J.-M.; Cohen, D. Changes in the Use of Emergency Care for the Youth with Mental Health Problems Over Decades: A Repeated Cross Sectional Study. Front. Psychiatry 2019, 10, 26. [CrossRef] [PubMed]

13. Piovani, D.; Clavenna, A.; Bonati, M. Prescription prevalence of psychotropic drugs in children and adolescents: An analysis of international data. Eur. J. Clin. Pharmacol. 2019, 75, 1333-1346. [CrossRef]

14. Sills, M.R.; Bland, S.D. Summary Statistics for Pediatric Psychiatric Visits to US Emergency Departments, 1993-1999. Pediatrics 2002, 110, e40. [CrossRef] [PubMed]

15. Kendrick, J.G.; Goldman, R.D.; Carr, R.R. Pharmacologic Management of Agitation and Aggression in a Pediatric Emergency Department-A Retrospective Cohort Study. J. Pediatr. Pharmacol. Ther. 2018, 23, 455-459. [CrossRef] [PubMed]

16. Riva, B.; Clavenna, A.; Cartabia, M.; Bortolotti, A.; Fortino, I.; Merlino, L.; Biondi, A.; Bonati, M. Emergency department use by paediatric patients in Lombardy Region, Italy: A population study. BMJ Paediatr. Open 2018, 2, e000247. [CrossRef] [PubMed]

17. Simeon, J.G.; Ferguson, H.B.; Knott, V.; Roberts, N.; Gauthier, B.; Dubois, C.; Wiggins, D. Clinical, Cognitive, and Neurophysiological Effects of Alprazolam in Children and Adolescents with Overanxious and Avoidant Disorders. J. Am. Acad. Child Adolesc. Psychiatry 1992, 31, 29-33. [CrossRef]

18. Graae, F.; Milner, J.; Rizzotto, L.; Klein, R.G. Clonazepam in Childhood Anxiety Disorders. J. Am. Acad. Child Adolesc. Psychiatry 1994, 33, 372-376. [CrossRef]

19. Connolly, S.D.; Bernstein, G.A. Practice Parameter for the Assessment and Treatment of Children and Adolescents with Anxiety Disorders. J. Am. Acad. Child Adolesc. Psychiatry 2007, 46, 267-283. [CrossRef]

20. Katzman, M.A.; Bleau, P.; Blier, P.; Chokka, P.; Kjernisted, K.; Van Ameringen, M.; The Canadian Anxiety Guidelines Initiative Group on behalf of the Anxiety Disorders Association of Canada/Association Canadienne des troubles anxieux and McGill University. Canadian clinical practice guidelines for the management of anxiety, posttraumatic stress and obsessive-compulsive disorders. BMC Psychiatry 2014, 14, S1. [CrossRef]

21. NICE. Social Anxiety Disorder: Recognition, Assessment and Treatment. Clinical Guideline [CG159]. Available online: https://www.nice.org.uk/guidance/cg159 (accessed on 24 July 2020).

22. Sonnier, L.; Barzman, D. Pharmacologic Management of Acutely Agitated Pediatric Patients. Pediatr. Drugs 2011, 13, 1-10. [CrossRef] [PubMed]

23. Marzullo, L.R. Pharmacologic Management of the Agitated Child. Pediatr. Emerg. Care 2014, 30, $269-275$. [CrossRef] [PubMed]

24. Gerson, R.; Malas, N.; Feuer, V.; Silver, G.; Prasad, R.; Mroczkowski, M.M.; De Pena-Nowak, M.; Gaveras, G.; Goepfert, E.; Hartselle, S.; et al. Best Practices for Evaluation and Treatment of Agitated Children and Adolescents (BETA) in the Emergency Department: Consensus Statement of the American Association for Emergency Psychiatry. West. J. Emerg. Med. 2019, 20, 409-418. [CrossRef] [PubMed]

25. Loy, J.H.; Merry, S.N.; E Hetrick, S.; Stasiak, K. Atypical antipsychotics for disruptive behaviour disorders in children and youths. Cochrane Database Syst. Rev. 2017, 8, CD008559. [CrossRef]

26. NICE Guidelines. Antisocial Behavior and Conduct Disorders in Children and Young People: Recognition, Intervention and Management. Available online: https://www.nice.org.uk/guidance/cg158 (accessed on 24 July 2020).

27. Morganti, C.; Allevi, L.; Poli, R.; Lugo, F.; Durbano, F.; Laini, V.; Malchiod, F.; Cescon, A.M.; Ferrario, E.; Panariello, A.; et al. Percorso per la Gestione dell'Agitazione Psicomotoria in Area Critica e nei Reparti di Degenza nell'adulto e in età evolutiva. Milano. 2012. Available online: https:/docplayer.it/39177877-Percorso-per-la-gestione-dell-agitazione-psicomotoria-in-area-critica-e-neireparti-di-degenza-nell-adulto-e-in-eta-evolutiva.html (accessed on 24 July 2020).

28. Bem, C.; Small, N. An ecological framework for improving child and adolescent health. Arch. Dis. Child. 2020, 105, 299-301. [CrossRef] 
29. Segal, L.; Guy, S.; Leach, M.J.; Groves, A.; Turnbull, C.; Furber, G. A needs-based workforce model to deliver tertiary-level community mental health care for distressed infants, children, and adolescents in South Australia: A mixed-methods study. Lancet Public Health 2018, 3, e296-e303. [CrossRef]

30. Kazdin, A.E. Annual Research Review: Expanding mental health services through novel models of intervention delivery. J. Child Psychol. Psychiatry 2019, 60, 455-472. [CrossRef]

Publisher's Note: MDPI stays neutral with regard to jurisdictional claims in published maps and institutional affiliations.

(C) 2020 by the authors. Licensee MDPI, Basel, Switzerland. This article is an open access article distributed under the terms and conditions of the Creative Commons Attribution (CC BY) license (http://creativecommons.org/licenses/by/4.0/). 